\title{
Dynamic testing of surface support systems
}

\author{
R Brändle Geobrugg AG, Switzerland \\ R Luis Fonseca Geobrugg Ibérica S.A., Spain
}

\begin{abstract}
Ground support for dynamic conditions must be able to withstand the associated loads and deformations and the support scheme has to work as a system. In order to prove the suitability of such support systems with high-tensile steel mesh and bolts and to analyse the bearing behaviour of them, a large-scale test setup was commissioned in Walenstadt, Switzerland. On this test rig it is possible to apply large energies on variable ground support systems with variable bolt patterns and meshes with a total support area of $3.6 \times 3.6 \mathrm{~m}$ in a full-scale manner. The test site is instrumented by load cells, high-speed video analysis and accelerometers. In this paper the analysis of the load cells, the accelerometers and the high-speed video cameras is given and results of system tests are discussed. It could be shown that a combination of high-tensile steel mesh with a specific bolt pattern can result in high energy capacity surface support. Distribution of the impact loads during the stopping process to the different elements of the bearing support system depends on the strength and flexibility of the mesh and the bolts resistance and his pattern.
\end{abstract}

Keywords: dynamic test, full-scale setup, system test

\section{Introduction}

Mining is getting deeper, and rockburst damage is a growing risk in underground excavations around the world. Especially in mining tunnels, when in search of the mineral strata, tunnels are deepened more and more, until reaching depths exceeding $1,000 \mathrm{~m}$. However, these seismicity events and associated rockburst can occur, even at smaller depths.

The desire to increase the energy dissipation capacity in the support system designs of different mines was made many years ago. With this final goal, systematic studies have been carried out, aiming to improve the performance of the single elements and the complete reinforcement systems.

In addition, the development of diamond-shaped lightweight steel wire membranes of very high tensile strength in recent years has given a great turnaround to this trend. These powerful flexible solutions combined with suitable anchors are a huge step towards solving situations where protection against dynamic load is imperative.

\section{$2 \quad$ High-tensile strength steel wire membranes}

The high-tensile wire $(1,770 \mathrm{MPa})$ mesh offers a surface support for many different ground conditions. The mesh is made from high-tensile steel wire with a diameter of 4 and/or $3 \mathrm{~mm}$. The mesh has a specifically developed diamond shape to minimise deformations, and along the edges each spiral wire is looped and twisted back on itself (Figure 1). This enables the edge of the mesh to have the same loading capacity as the mesh (Luis Fonseca et al. 2009). In terms of corrosion protection, the wires are coated with a special aluminium-zinc coating, which has a higher corrosion resistance than standard zinc galvanising. 


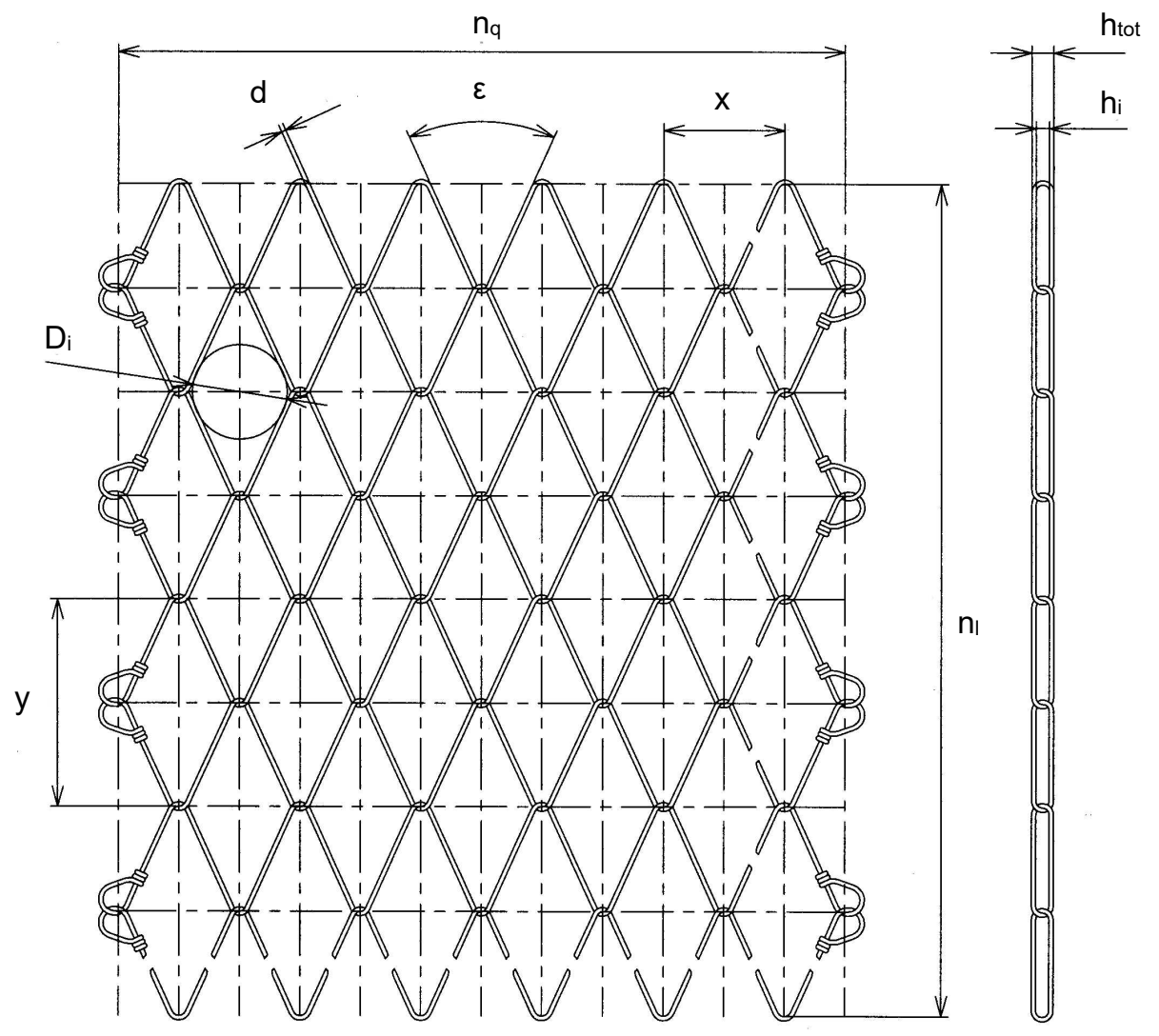

Figure 1 Principal drawing of diamond-shaped high-tensile mesh

The resistance properties of the mesh were determined in a series of laboratory tests (2002) at the University of Cantabria, Spain. The properties of the meshes are summarised in Table 1.

Table 1 Properties of high-tensile mesh

\begin{tabular}{lll}
\hline Material & MINAX 65/4 & MINAX 80/4 \\
\hline Mesh width & $63 \mathrm{~mm}$ & $80 \mathrm{~mm}$ \\
Diagonal & $83 \times 138 \mathrm{~mm}$ & $102 \times 177 \mathrm{~mm}$ \\
Wire diameter & $4 \mathrm{~mm}$ & $4 \mathrm{~mm}$ \\
Wire strength & $1,770 \mathrm{MPa}$ & $1,770 \mathrm{MPa}$ \\
Breaking load of wire & $22 \mathrm{kN}$ & $22 \mathrm{kN}$ \\
Tensile strength & $250 \mathrm{kN} / \mathrm{m}$ & $190 \mathrm{kN} / \mathrm{m}$ \\
Weight & $3.3 \mathrm{~kg} / \mathrm{m}^{2}$ & $2.6 \mathrm{~kg} / \mathrm{m}^{2}$ \\
\hline
\end{tabular}

\section{Dynamic impact large-scale test}

A series of large-scale tests were conducted during 2017 and 2018 in a quarry in Walenstadt (rockfall testing facility) Switzerland described in Aschwanden \& Murri (2018). The main goals for performing large-scale tests were to increase knowledge about the behaviour and the interaction of ground and the anchored flexible support in front dynamic load and checking the reliability and validation of the dimensioning assumptions, based on test site observations and back calculations. Initial experiments of the test programme allowed for observation and optimisation of the test setup, testing procedure and data acquisition method. After 
optimisation of the test setup the following experiments were conducted in a repetitive way to guarantee reliable and comparable experimental results.

The dynamic load is reproduced by dropping a block of reinforced concrete. The accelerations in the three main axes were measured on the top of the barrel. In addition, the forces acting during the test on the anchors have been detected by measurement equipment. The test was recorded with two high-speed and two real-time cameras. The deflection was determined with a high-speed camera from the side.

\subsection{Test arrangement}

The test device is composed of a platform with two levels of square-shaped pyramidal trunk geometries (Figure 2), in the upper level housing the impact set consisting of a 9,640 kg concrete block dropped from a height of $4.9 \mathrm{~m}$ resulting in $463 \mathrm{~kJ}$ of impact energy. The concrete block is guided with steel profiles. The lower level is composed of a shotcrete slab, together with the mesh layers fixed by anchors, which are attached to the upper level. A copper contact was mounted on the steel plate to determine the moment of first contact.

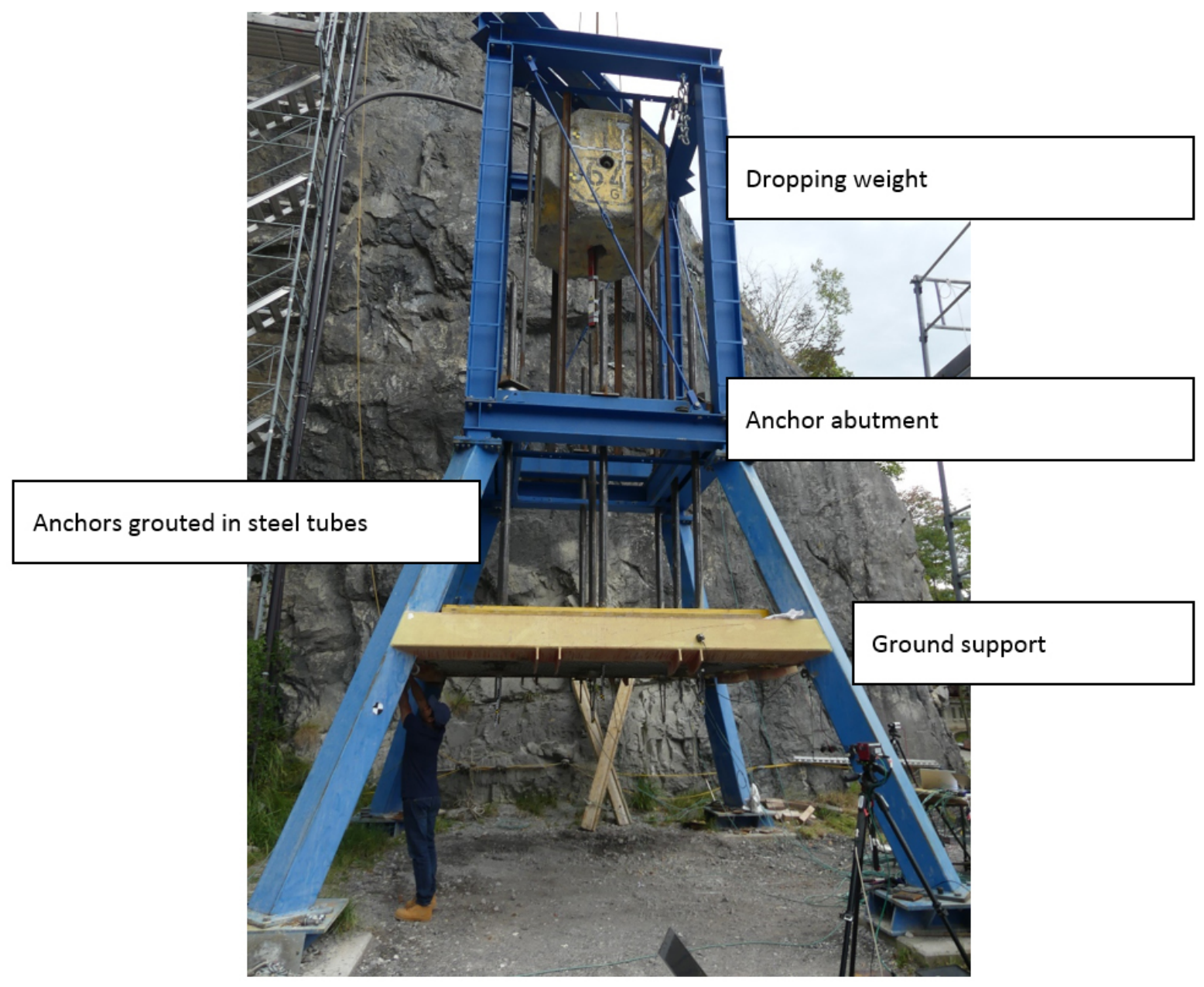

Figure 2 Test arrangement

\subsubsection{Ground support setup}

The tested ground support consists of a first layer of MINAX 80/4 high-tensile mesh covered in $10 \mathrm{~cm}$ concrete anchored with five solid threaded bars (diameter $25 \mathrm{~mm}$, yield strength $500 \mathrm{~N} / \mathrm{mm}^{2}$, load at yield $245 \mathrm{kN}$ ) and a second MINAX 65/4 outside the concrete anchored with four twin cable anchors (diameter $15.7 \mathrm{~mm}$, yield strength $1,770 \mathrm{~N} / \mathrm{mm}^{2}$, load at yield $218 \mathrm{kN}$ ) (Figures 3 and 5). This ground support scheme is currently used in a copper mine in Chile. On top of the ground support is a layer of $0.30 \mathrm{~m}$ of simulated rock mass. This 
should distribute the load to the complete support system. The solid threaded bars are grouted in steel tubes with an inner diameter of $70 \mathrm{~mm}$ which simulates the boreholes. The steel tubes are cut $0.6 \mathrm{~m}$ above the simulated rock mass to simulate a discontinuity (Figure 4). These threaded bars have a decoupled length of $1.0 \mathrm{~m}$ around the simulated discontinuity to allow a deformation and dissipate some of the energy. All twin cable bolts are grouted over the full length in the steel tubes. Steel plates are installed in the simulated rock mass and welded onto the steel tubes to transfer load of the impact to the bolts and cables not just with the end plate.

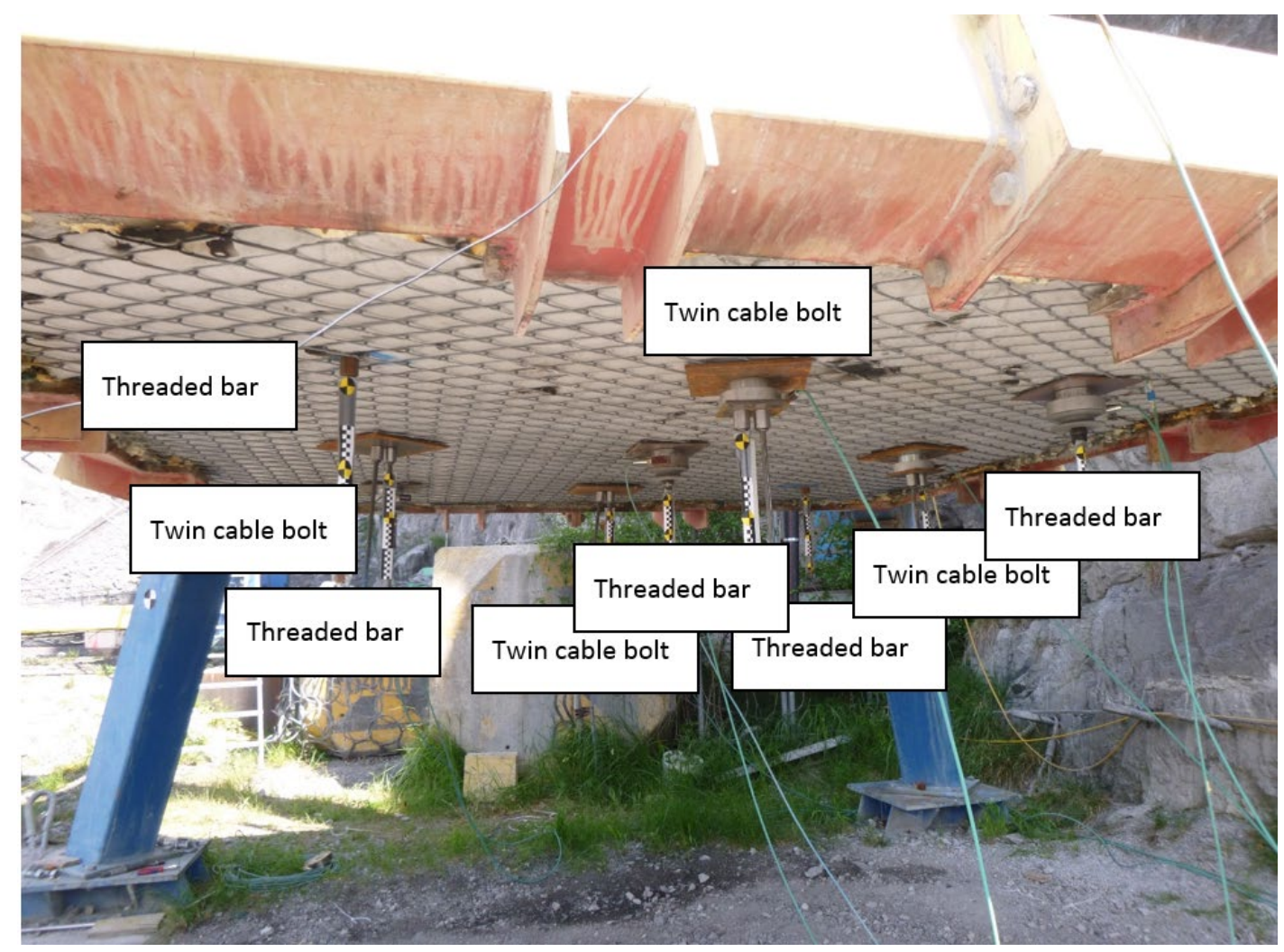

Figure 3 View from below with MINAX 65/4, four twin cable bolts and five threaded bars
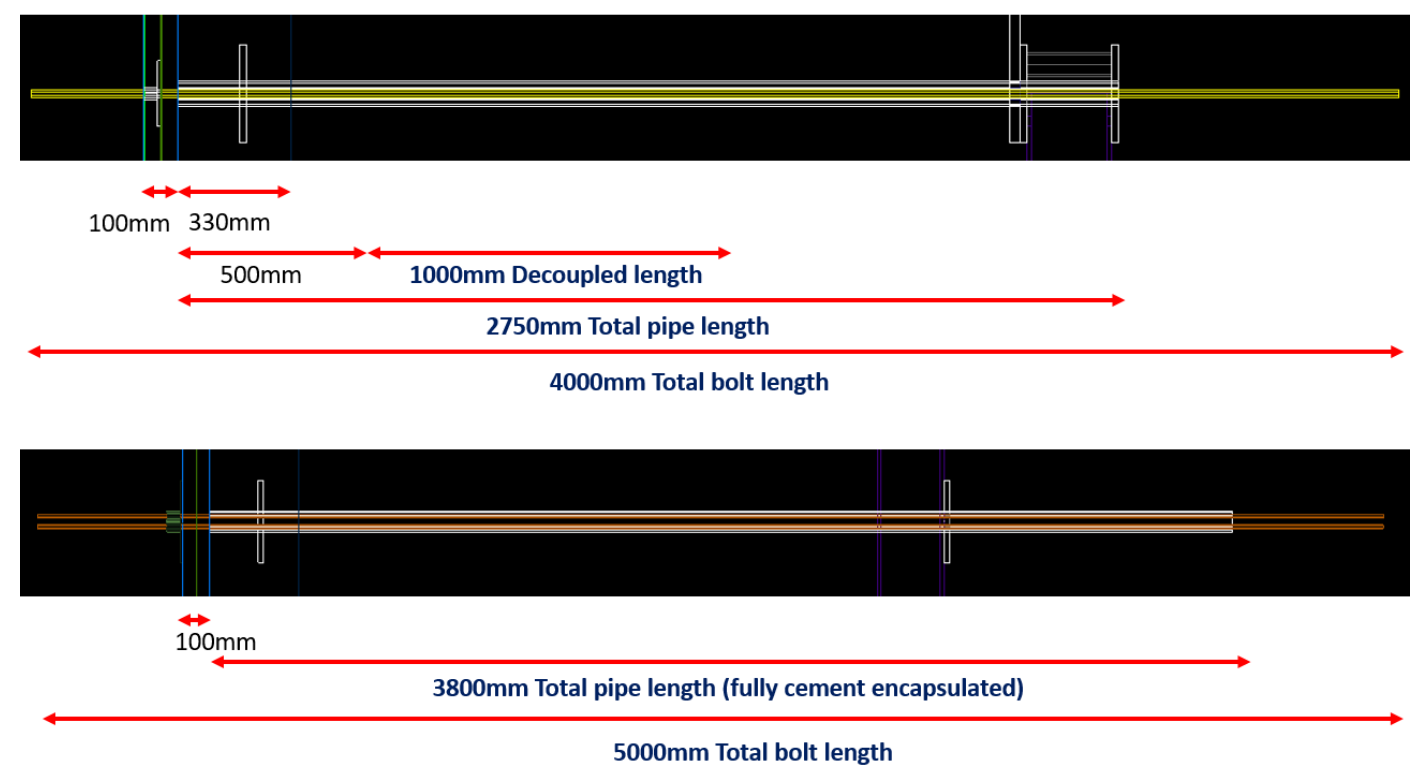

Figure 4 Scheme of threaded bars and twin strand cables 


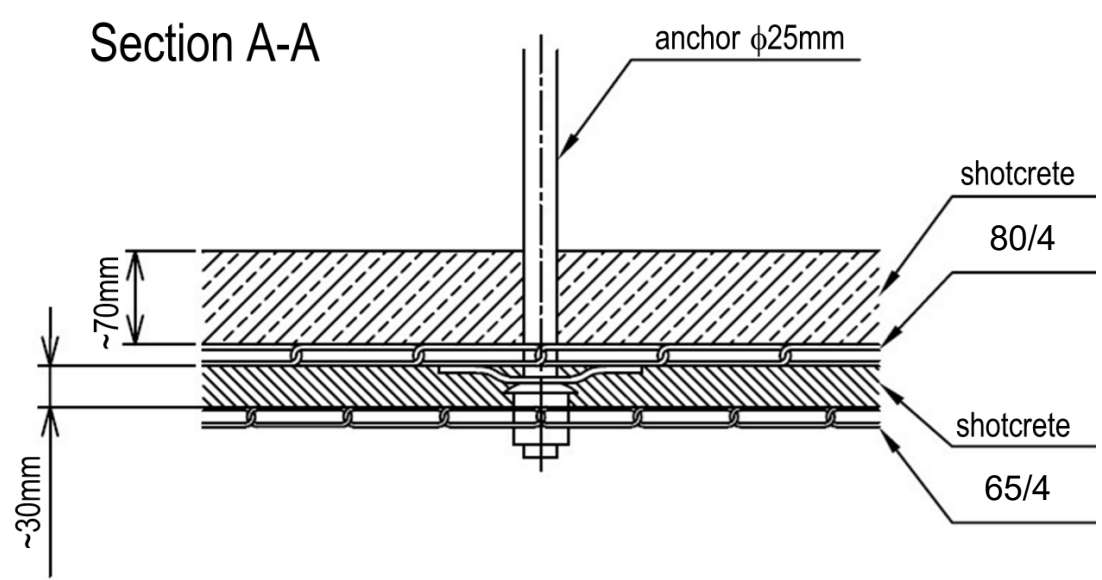

Figure 5 Scheme of meshes installed

\subsubsection{Measurement and data recording}

The accelerations of the block were measured in the middle of the top surface using a three-axis accelerometer $(2,000 \mathrm{~g})$. In-dummy measuring technology was used; the same technology which is used in crash-test dummies. The data storage is performed directly in the sensors (Figure 6). The sensors record the measured data completely even with interruption of the connecting cable. After the test, the sensor will be reconnected with the gateway for downloading the information data. The forces were measured with load cells at five anchors (Figure 7), the solid bars at the abutment after the first layer of mesh and after the second layer of mesh. The twin cable anchors just at the top and after the mesh. Displacement of anchors have been measured by high-speed video.

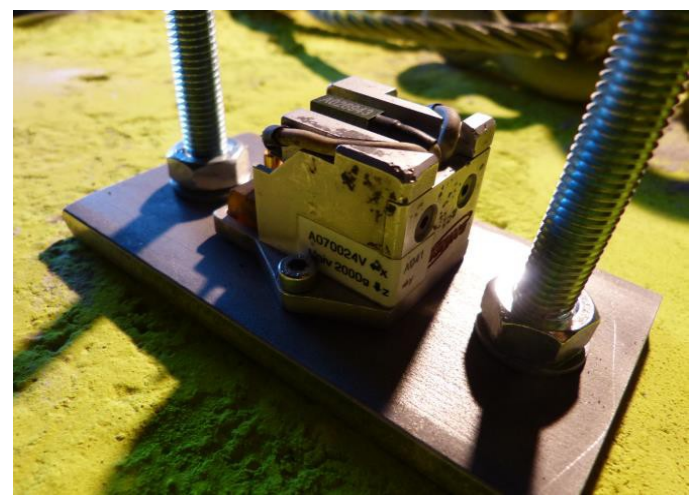

Figure 6 Three-axis accelerometer

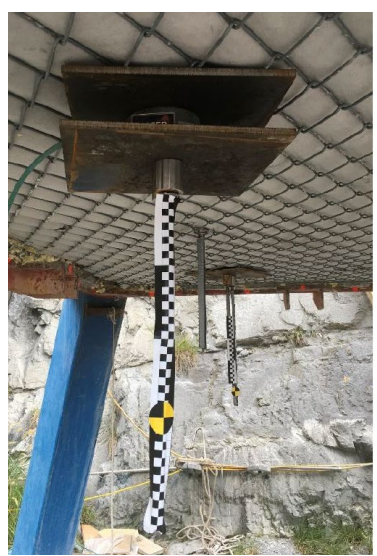

(a)

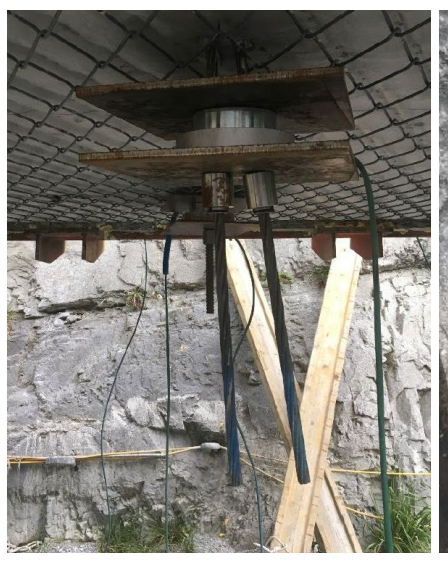

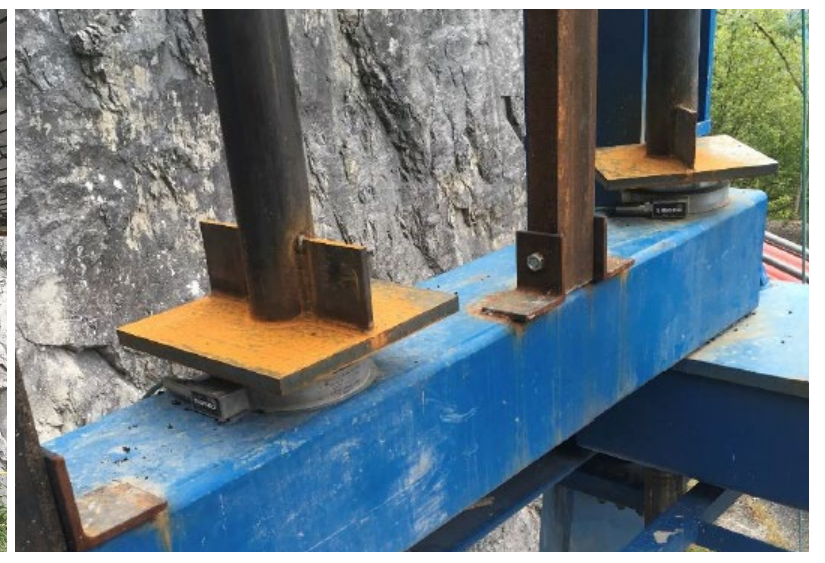

(b)

Figure 7 Load cell installation at (a) Solid bar and twin strand cable; (b) Abutment 
The coordinates system origin (zero-point) is in the middle of the shotcrete floor, where the barrel hits the metal plate on the shotcrete slab floor: $+X$ (positive right) $+Y$ (positive back) and $+Z$ (positive upwards) (Figure 8).

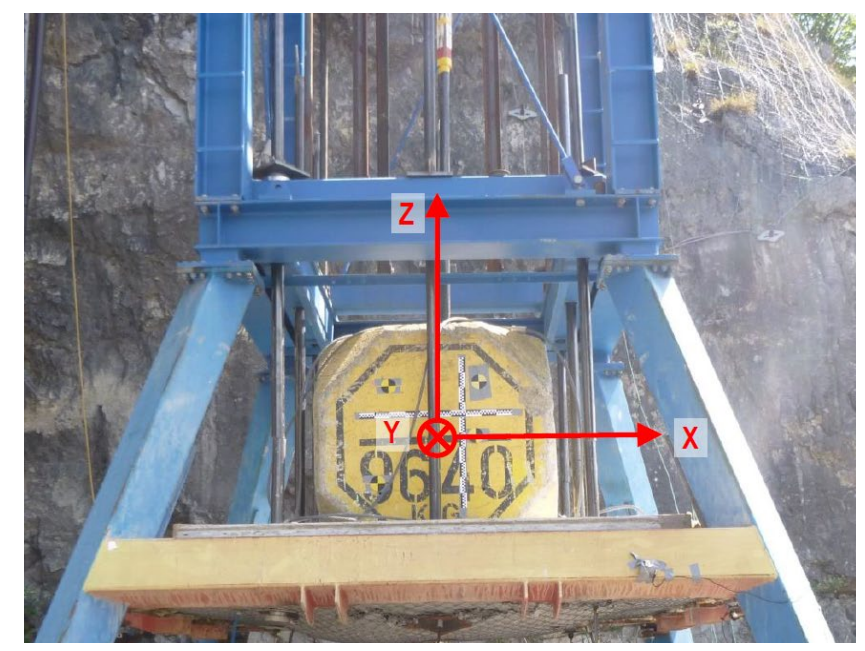

Figure 8 Coordinates system origin

\subsection{Test results}

On 4 June 2018, a full-scale test with an impact energy of $463 \mathrm{~kJ}$ has been conducted (Figure 9). The 9,640 $\mathrm{kg}$ concrete block was dropped down from a height of $4.90 \mathrm{~m}$ onto the simulated rock mass above the ground support. The block was completely restrained by the ground support system. Two of the twin strand cable bolts tore off, as did the solid bar in the centre (Figure 10). The MINAX 65/4 outside the concrete had no visible damage.
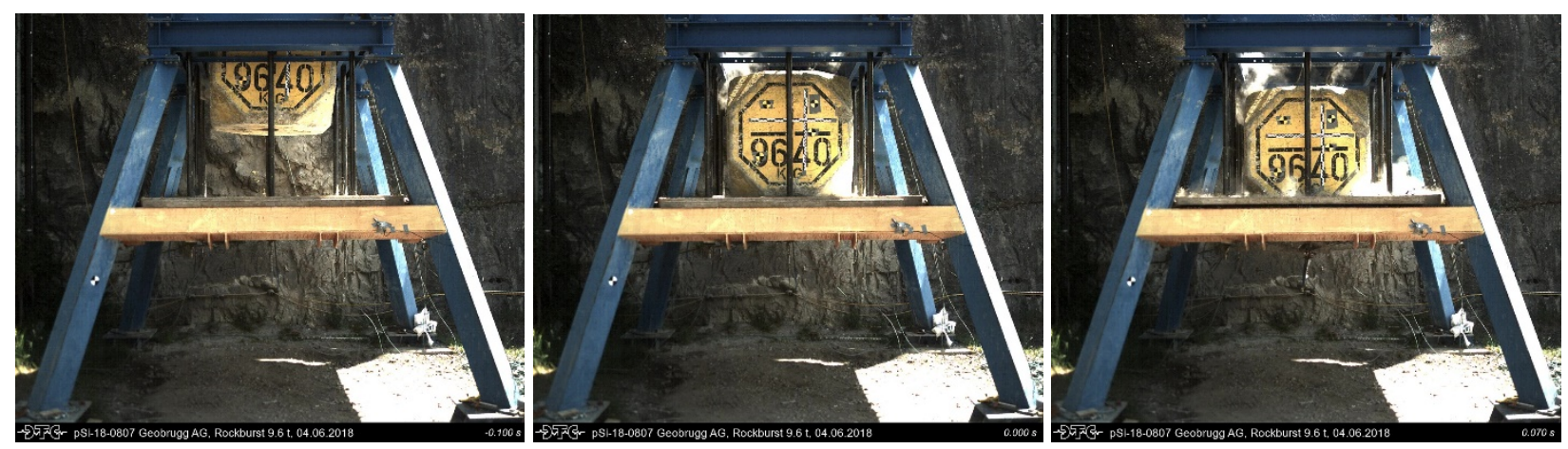

Figure 9 Impact of the concrete block onto the simulated rock mass 


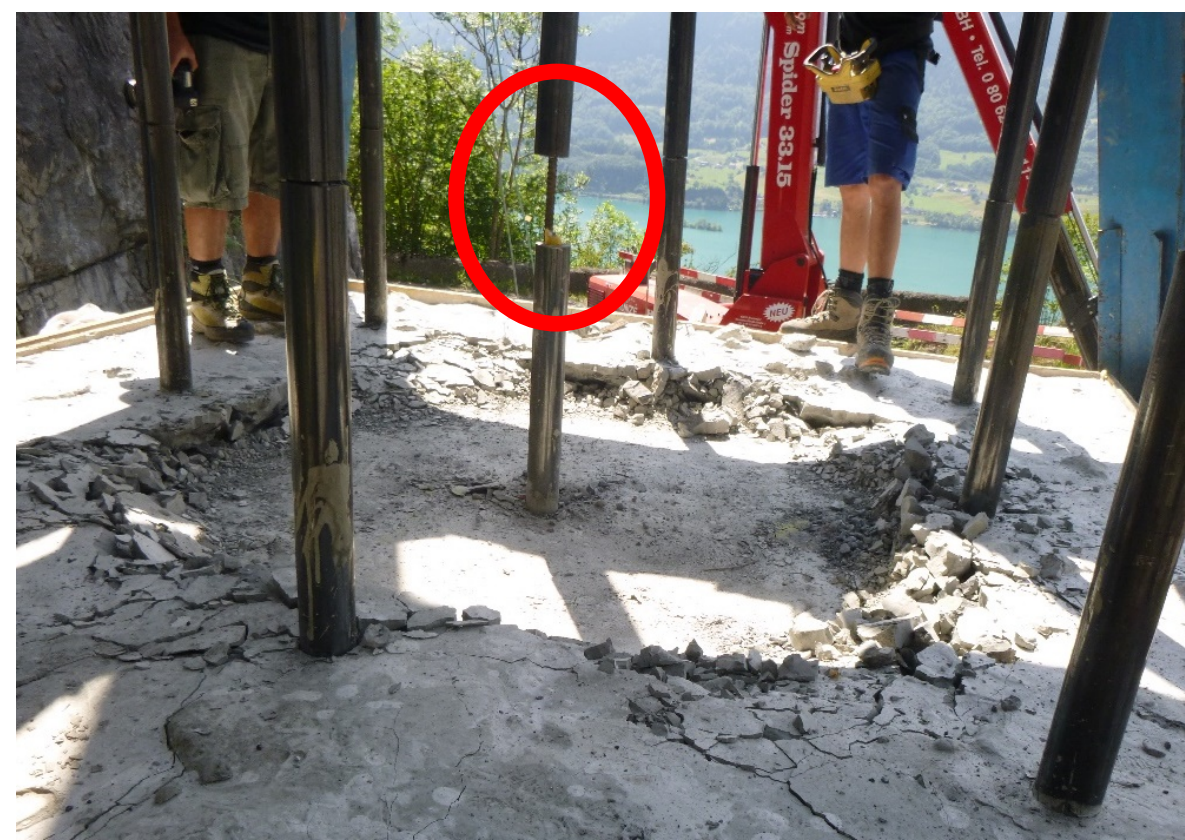

Figure 10 Simulated rock mass after impact. Visible deformation of centre bolt

\subsubsection{Measurement and data}

Measured anchor loads show realistic values compared to video observations (Figure 11). The broken centre bolt (anchor No. 5, solid bar $25 \mathrm{~mm}$ diameter) showed a max value at the top of $288 \mathrm{kN}$ which is equal to the characteristic breaking load of the solid bar.

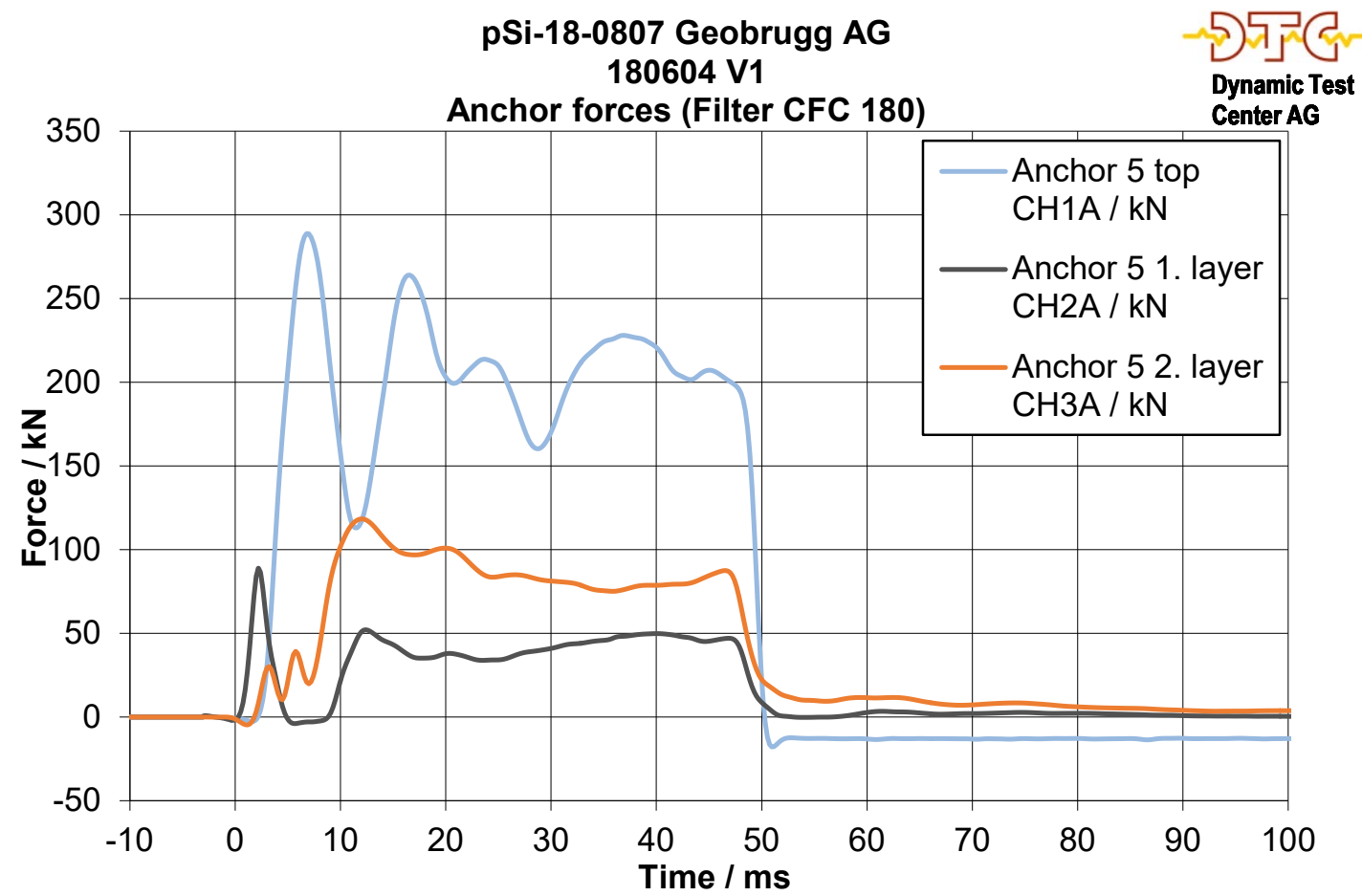

Figure 11 Measured forces in the centre bolt, anchor No. 5

The solid bars in the corners (anchor No. 1 and No. 9) received significantly less load compared to the twin cable bolts on the sides (anchor No. 6 and No. 8). This can be explained with their location as the anchors in the corner are further from the impact area of the concrete block installed, and with the shape of the 
concrete block. One cable in twin cable bolt No. 2 and one in twin cable bolt No. 8 tore off (Figure 12). There was no visible damage to the mesh.

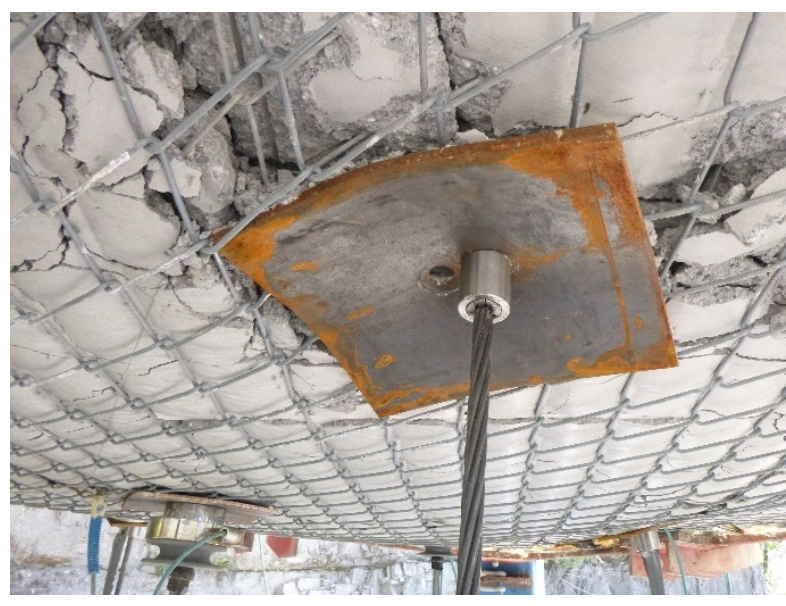

(a)

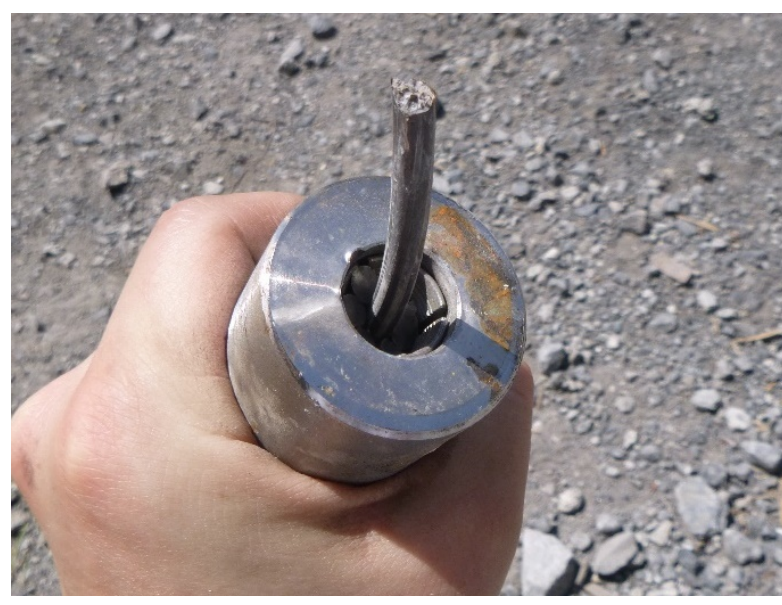

(b)

Figure 12 (a) Snapped cable bolt; (b) Twin cable bolt No. 2

\section{Conclusion}

Dynamic laboratory tests contribute to the primary knowledge and establish initial parameters of comparison between different elements. However, the need to work at a small scale limits the possibilities of a perfect simulation of the reality and, therefore, it is important to understand how the test is carried out and the significance of the results.

The characteristics of a lab test that attempts to reproduce the conditions of a mine, will always be an approximation to the conditions on site. However, it allows comparisons between systems/elements of fortification and helps to advance in understanding the complex problem of ground support.

With this successful test of a reinforcement system (shotcrete with mesh, bolt and a second mesh with cable bolts) under dynamic conditions, we can add experimental antecedents to the theory and confirm that this type of support may be beneficial in use in potential rockburst areas.

The elements of the measurement system (load sensors, accelerometers and high-speed video cameras) showed their suitability in obtaining data. The detailed description of each test also gives data related with acceleration and displacement of the system after impact.

\section{Acknowledgement}

The authors acknowledge that The Southern African Institute of Mining and Metallurgy (SAIMM) first published this paper in the Proceedings of the Ninth International Conference on Deep and High Stress Mining and thank SAIMM for their permission to republish.

\section{References}

Luis Fonseca, R, Laguna, L \& Muñoz, B 2009, 'Comparative analysis of the mechanical properties of the steel membranes for slope stabilization', VII National Symposium on Unstable Hills and Slopes, Barcelona.

Aschwanden, F \& Murri, R 2018, Test Documentation of the Rockburst Impact Test, Performed on June 4, 2018 , Report No. pSi-18-0807, Dynamic Test Center AG, Vauffelin/Biel. 